\title{
PENGARUH BIMBINGAN TEHNIK MENYIKAT GIGI TERHADAP STATUS KEBERSIHAN GIGI DAN MULUT ANAK TUNAGRAHITA
}

\author{
ELDARITA, RIZQI AMANULLAH \\ Politeknik Kemenkes Yogyakarta \\ rita.elda@yahoo.co.id
}

\begin{abstract}
Dental health education is used as a measuring tool to generate knowledge and awareness that can influence a person's attitudes and habits towards oral and dental hygiene. Low oral health knowledge can be affected to children's attitudes and actions. The study aims to determine the effect of guidance on the technique of brushing teeth on the oral hygiene status of mentally retarded children, the output of this study is expected to be useful as a reference in improving the ability of brushing techniques and oral and dental hygiene. The research design was quasy experimental design with a pre test and post test with control group approach. The study was conducted at SLB Wiyata Dharma 4 Godean Sleman in October 2019. Data analysis using t-test statistical tests. The results showed that there was an increase in knowledge, abilities and status of dental and oral hygiene of mentally retarded children. Statistical test results obtained $p$ value $=0.00$ The conclusion of the study was that there was a significant influence between the guidance of brushing teeth on the oral and dental hygiene status of mentally retarded children. It is recommended that mentally retarded children increase awareness and apply brushing knowledge in maintaining oral and dental hygiene.
\end{abstract}

Keywords: Guidance, teeth brushing technique, status of dental and oral hygiene, children with developmental disabilitas.

Abstrak: Pendidikan Kesehatan gigi digunakan sebagai alat ukur untuk membangkitkan pengetahuan dan kesadaran yang dapat mempengaruhi sikap dan kebiasaan seseorang terhadap kebersihan gigi dan mulut. Pengetahuan kesehatan gigi dan mulut yang rendah dapat mempengaruhi sikap dan tindakan anak. Penelitian bertujuan untuk mengetahui pengaruh bimbingan tehnik menyikat gigi terhadap status kebersihan gigi dan mulut anak tunagrahita, output penelitian ini diharapkan bermanfaat sebagai acuan dalam meningkatkan kemampuan tehnik menyikat gigi dan kebersihan gigi dan mulut. Disain penelitian adalah quasy experimental design dengan pendekatan rancangan pre test and post test with control group. Penelitian dilakukan di SLB Wiyata Dharma 4 Godean Sleman pada bulan Oktober 2019. Analisis data dengan uji statistik t-test. Hasil penelitian menunjukkan bahwa terdapat peningkatan pengetahuan, kemampuan dan status kebersihan gigi dan mulut anak tunagrahita. Hasil uji statistik didapat nilai $\mathrm{p}$ value $=0.00$ Kesimpulan penelitian adalah ada pengaruh signifikan antara bimbingan menyikat gigi terhadap status kebersihan gigi dan mulut anak tunagrahita. Disarankan agar anak tunagrahita meningkatkan kesadaran dan menerapkan pengetahuan menyikat gigi dalam menjaga kebersihan gigi dan mulut.

Kata Kunci: Bimbingan, tehnik menyikat gigi, Status Kebersihan Gigi dan Mulut, Anak Tunagrahita.

\section{A. Pendahuluan}

Pemeliharaan kesehatan gigi dan mulut secara keseluruhan dimulai dari kebersihan gigi dan mulut (Motto, 2017). Hasil Riskesdas 2018 menunjukkan proporsi masalah kesehatan gigi dan mulut sebesar 57,6\% dan proporsi menyikat gigi dengan 
benar 2,8\%. Proporsi perilaku menyikat gigi setiap hari pada penduduk Provinsi D.I. Yogyakarta sebesar 94,9\% namun hanya sebesar 6\% melakukan meyikat gigi dengan waktu tepat setelah sarapan pagi dan malam sebelum tidur (Kemenkes, RI., 2018).

Edukasi dan pelayanan kesehatan gigi mempengaruhi kebersihan rongga mulut. Meningkatkan perilaku anak menjaga kesehatan gigi dan mulut adalah dengan memberikan pengetahuan kesehatan gigi tentang cara menyikat gigi yang baik dan benar, dan menggunakan media yang tepat (Kristianto, dkk, 2018). Pendidikan Kesehatan gigi sebagai alat ukur pengetahuan dan kesadaran yang mempengaruhi sikap dan kebiasaan seseorang terhadap kebersihan gigi dan mulut. Pengetahuan kesehatan gigi dan mulut yang rendah dapat mempengaruhi sikap dan tindakan anak (Lossu dkk, 2015).

Anak berkebutuhan khusus dengan gangguan mental-intelektual salah satunya adalah anak tunagrahita, dikenal dengan reterdasi mental yakni anak dengan keterbatasan dalam fungsi intelektual dibawah rata-rata. Hal ini menyebabkan kesulitan melakukan adaptasi lingkungan dan keterbatasan keterampilan adaptasi dengan lingkungan seperti berkomunikasi, merawat diri sendiri, keterampilan sosial, fungsi akademis, kesehatan dan keamanan. Anak tunagrahita dapat menjadi anak yang mempunyai kepercayaan diri, mandiri, mampu merawat diri dan melaksanakan tugastugas sederhana apabila lingkungannya dapat memberikan dukungan dan bimbingan (Wati, 2012).

Penelitian Tulangwo (2015), menyatakan hasil pemeriksaan status karies gigi menunjukkan indeks DMF-T anak tunagrahita memiliki kategori sedang yang dimiliki oleh anak tunagrahita ringan $100 \%$, sedangkan pada anak tunagrahita sedang status karies sedang dengan persentase $87 \%$. Menurut peneliti karies pada anak tunagrahita memiliki keterkaitan dengan masalah medis yang merupakan akibat dari penyakit atau kondisi yang tidak sempurna, seperti akibat infeksi, gangguan waktu kehamilan dan masalah gigi atau rongga mulut yang dapat membahayakan kesehatan umum.

Sekolah Luar Biasa (SLB), salah satu bentuk pendidikan khusus mengenai anakanak berkelainan sebagai objek formal dan materialnya dari berbagai jenis kelainan termasuk anak tunagrahita. Hasil studi pendahuluan Juni 2019 di SLB-C Wiyata Dharma IV Godean melalui wawancara kepada beberapa anak tunagrahita tentang cara menyikat gigi, menunjukkan bahwa hampir $85 \%$ anak menyikat gigi dengan gerakan sikat hanya maju mundur saja di semua permukaan gigi dan waktu menyikat gigi dilakukan bersamaan dengan mandi pagi dan sore. Hasil pemeriksaan kebersihan gigi dan mulut anak tunagrahita sebagian besar $(80 \%)$ pada kriteria buruk.

\section{B. Metodologi Penelitian}

Disain penelitian quasy experimental design dengan rancangan pre test and post test with control group. Populasi penelitian seluruh anak tunagrahita ringan dan sedang di SLB Wiyata Dharma IV Godean. Pengambilan sampel dengan metode pengambilan total sampling. Sampel penelitian berjumlah 60 orang. Alat pengumpulan data yaitu alat diagnose set (kacamulut, sonde, pinset, excavator), gelas kumur, dan format pemeriksaan. Uji statistik yang digunakan adalah paired sampel ttest. 


\section{Hasil dan Pembahasan}

\section{Gambaran Umum Responden Penelitian}

Tabel 1. Karakteristik Responden berdasarkan Jenis Kelamin

\begin{tabular}{ccccccc}
\hline \multirow{2}{*}{ Jenis kelamin } & \multicolumn{4}{c}{ Kelompok } & \multicolumn{2}{c}{ Total } \\
\cline { 2 - 5 } & \multicolumn{2}{c}{ Perlakuan } & \multicolumn{2}{c}{ Kontrol } & \multicolumn{2}{c}{} \\
\cline { 2 - 5 } & $\mathrm{f}$ & $\%$ & $\mathrm{f}$ & $\%$ & $\mathrm{f}$ & $\%$ \\
\hline Laki-laki & 19 & 63.3 & 14 & 46.7 & 33 & 55 \\
Perempuan & 11 & 36.7 & 16 & 53.3 & 27 & 45 \\
\hline Umur & & & & & & \\
\hline $8-9$ tahun & 15 & 50 & 13 & 43 & 28 & 47 \\
\hline $10-12$ tahun & 15 & 50 & 17 & 57 & 32 & 53 \\
\hline Total & 30 & 100 & 30 & 100 & 60 & 100 \\
\hline
\end{tabular}

Berdasarkan tabel 1 diketahui bahwa responden berjenis kelamin laki-laki dan umur 10-12 tahun kelompok terbanyak.

Tabel 2. Distribusi Frekuensi Pengetahuan Responden Sebelum dan Sesudah Penyuluhan Tehnik Menyikat Gigi.

\begin{tabular}{ccccccccc}
\hline Pengetahuan & \multicolumn{3}{c}{ Kelompok Perlakuan } & \multicolumn{3}{c}{ Kelompok Kontrol } \\
& \multicolumn{2}{c}{ Pre-test } & \multicolumn{2}{c}{ Post-Test } & \multicolumn{2}{c}{ Pre-test } & \multicolumn{2}{c}{ Post-Test } \\
& $\mathrm{n}$ & $\%$ & $\mathrm{n}$ & $\%$ & $\mathrm{n}$ & $\%$ & $\mathrm{n}$ & $\%$ \\
\hline Baik & 6 & $20 \%$ & 14 & $47 \%$ & 5 & $17 \%$ & 9 & $30 \%$ \\
Sedang & 13 & $43 \%$ & 13 & $43 \%$ & 12 & $40 \%$ & 14 & $47 \%$ \\
Kurang & 11 & $37 \%$ & 13 & $10 \%$ & 13 & $43 \%$ & 7 & $23 \%$ \\
Total & 30 & $100 \%$ & 30 & $100 \%$ & 30 & $100 \%$ & 30 & $100 \%$ \\
\hline Mean & 7.33 & & 9.63 & & 6.93 & & 9.37 & \\
Std.Deviation & 2.89 & & 3.27 & & 3.41 & & 3.47 & \\
\hline
\end{tabular}

Berdasarkan tabel 2 diketahui pengetahuan menyikat gigi responden sebelum dan sesudah dilakukan penyuluhan paling banyak pada kategori sedang (43\%).

Tabel 3. Distribusi Frekuensi Kemampuan Responden Sebelum dan Sesudah Bimbingan Tehnik Menyikat Gigi.

\begin{tabular}{ccccccccc}
\hline Kemampuan & \multicolumn{3}{c}{ Kelompok Perlakuan } & \multicolumn{3}{c}{ Kelompok Kontrol } \\
\hline & \multicolumn{2}{c}{ Pre-test } & \multicolumn{2}{c}{ Post-Test } & \multicolumn{2}{c}{ Pre-test } & \multicolumn{2}{c}{ Post-Test } \\
& $\mathrm{n}$ & $\%$ & $\mathrm{n}$ & $\%$ & $\mathrm{n}$ & $\%$ & $\mathrm{n}$ & $\%$ \\
\hline Baik & 8 & $27 \%$ & 13 & $43 \%$ & 8 & $27 \%$ & 11 & $37 \%$ \\
Sedang & 12 & $40 \%$ & 14 & $47 \%$ & 12 & $40 \%$ & 14 & $47 \%$ \\
Kurang & 10 & $33 \%$ & 3 & $10 \%$ & 10 & $33 \%$ & 5 & $17 \%$ \\
\hline Total & 30 & $100 \%$ & 30 & $100 \%$ & 30 & $100 \%$ & 30 & $100 \%$ \\
\hline Mean & 57,1 & & 63.9 & & 66.5 & & 9.37 & \\
Std.Deviation & 12.9 & & 14.2 & & 12.4 & & 3.47 & \\
\hline
\end{tabular}

Tabel 3 menunjukkan kemampuan kriteria baik dalam tehnik menyikat gigi responden kelompok perlakuan sebelum bimbingan $27 \%$ dan sesudah dilakukan bimbingan cara menyikat gigi meningkat menjadi 43\%. Kemampuan kelompok kontrol kriteria baik 
sebelum bimbingan hanya $27 \%$ dan sesudah dilakukan bimbingan cara menyikat gigi meningkat menjadi $37 \%$.

Tabel 4. Distribusi Frekuensi Status Kebersihan Gigi dan Mulut Responden Sebelum dan Sesudah Bimbingan Tehnik Menyikat Gigi

\begin{tabular}{ccccccccc}
\hline OHIS & \multicolumn{3}{c}{ Kelompok Perlakuan } & \multicolumn{3}{c}{ Kelompok Kontrol } \\
\hline & \multicolumn{2}{c}{ Pre-test } & \multicolumn{2}{c}{ Post-Test } & \multicolumn{2}{c}{ Pre-test } & \multicolumn{2}{c}{ Post-Test } \\
& $\mathrm{n}$ & $\%$ & $\mathrm{n}$ & $\%$ & $\mathrm{n}$ & $\%$ & $\mathrm{n}$ & $\%$ \\
\hline Baik & 7 & $23 \%$ & 15 & $50 \%$ & 7 & $23 \%$ & 11 & $37 \%$ \\
Sedang & 14 & $47 \%$ & 12 & $40 \%$ & 13 & $43 \%$ & 12 & $40 \%$ \\
Kurang & 9 & $30 \%$ & 3 & $10 \%$ & 10 & $34 \%$ & 7 & $23 \%$ \\
\hline Total & 30 & $100 \%$ & 30 & $100 \%$ & 30 & $100 \%$ & 30 & $100 \%$ \\
\hline Mean & 2.27 & & 1.86 & & 2.56 & & 1.76 & \\
Std.Deviation & 1.25 & & 1.18 & & 1.54 & & .99 &
\end{tabular}

Tabel 4 menunjukkan bahwa status kebersihan gigi dan mulut responden kelompok perlakuan sebelum bimbingan menyikat gigi pada kriteria baik hanya $23 \%$, setelah perlakuan meningkat menjadi 50\%. Responden kelompok kontrol sebelum bimbingan menyikat gigi pada kriteria baik $23 \%$, setelah perlakuan hanya meningkat menjadi $37 \%$.

Tabel 5. Hasil Uji Normalitas Sebaran Data Penelitian Antar Kelompok

\begin{tabular}{cccccc}
\hline \multirow{2}{*}{ Variabel } & \multicolumn{2}{c}{ Pre- Test } & \multicolumn{3}{c}{ Post_Test } \\
\cline { 2 - 5 } & $\begin{array}{c}\text { Nilai } \\
\text { Kolmogorov- } \\
\text { Smirnov Z }\end{array}$ & $\mathrm{p}$ & $\begin{array}{c}\text { Nilai } \\
\text { Kolmogorov- } \\
\text { Smirnov Z }\end{array}$ & Keterangan \\
\hline Pengetahuan & .258 & 1.00 & .645 & 0.79 & normal \\
Kemampuan & 0.00 & 1.00 & .258 & 1.00 & normal \\
OHIS & .129 & 0.00 & .516 & 0.95 & normal \\
\hline
\end{tabular}

Hasil uji normalitas data dengan Kolmogorov-Smirnov didapatkan nilai $p$ value $>0,05$ sehingga disimpulkan bahwa data memenuhi syarat normalitas.

Tabel 6. Hasil Uji Homogenitas Data Antar Kelompok

\begin{tabular}{cccc}
\hline Distribusi Variabel & \multicolumn{2}{c}{ Sig.(2-tailed) } & \multirow{2}{*}{ Keterangan } \\
\cline { 1 - 3 } & Pre Test & Post Test & \\
Pengetahuan & 0.80 & 0.76 & Homogen \\
Kemampuan & 1.00 & 0.92 & Homogen \\
OHIS & 0.73 & 0.70 & Homogen \\
\hline
\end{tabular}

Hasil uji homogenitas data menunjukkan bahwa $p>0.05$, sehingga dapat disimpulkan bahwa data tersebut memenuhi syarat homogenitas.

Tabel 7. Hasil Uji Paired T-Test Kelompok Perlakuan Sebelum dan Sesudah Bimbingan Menyikat Gigi.

\begin{tabular}{cccc}
\hline Data yang diuji & Mean \pm SD & T & $p$ \\
\hline Pre-test ke Post test Pengetahuan & $-2.30 \pm 3.39$ & 3.710 & 0.00
\end{tabular}




$\begin{array}{cccc}\text { Pre-test ke Post test Kemampuan } & -6.86 \pm 12.9 & -2.899 & 0.00 \\ \text { Pre-test ke Post test OHIS } & .69 \pm 1.53 & 2.318 & 0.02 \\ \text { Pengetahuan terhadap kemampuan } & 56,6 \pm 13.1 & 23.63 & 0.00 \\ \text { Kemampuan terhadap OHIS } & 55.2 \pm 13.2 & 22.90 & 0.00\end{array}$

Tabel 7. Menunjukkan terdapat perbedaan signifikan antara pengetahuan, kemampuan dan status kebersihan gigi dan mulut sebelum dan sesudah bimbingan menyikat gigi, terlihat dari $p$ value $<0,05$.

Tabel 8. Hasil Uji Paired T-Test Kelompok Kontrol Sebelum dan Sesudah Bimbingan Menyikat Gigi.

\begin{tabular}{cccc}
\hline Data yang diuji & Mean \pm SD & t & $p$ \\
\hline Pre-test ke Post test Pengetahuan & $-2.43 \pm 1.94$ & -6863 & 0.00 \\
Pre-test ke Post test Kemampuan & $-6.16 \pm 10.9$ & -4.596 & 0.00 \\
Pre-test ke Post test OHIS & $.80 \pm 1.28$ & 3.422 & 0.00 \\
Pengetahuan terhadap kemampuan & $-59.5 \pm 11.1$ & -29.19 & 0.00 \\
Kemampuan terhadap OHIS & $55.5 \pm 12.4$ & 24.45 & 0.00
\end{tabular}

Tabel 8. Menunjukkan terdapat perbedaan signifikan antara pengetahuan, kemampuan dan status kebersihan gigi dan mulut sebelum dan sesudah bimbingan menyikat gigi, terlihat dari $p$ value $<0,05$.

Tabel 9. Hasil Uji T-Test Kelompok Perlakuan dan Kontrol Sebelum dan Sesudah Bimbingan Menyikat Gigi.

\begin{tabular}{cccc}
\hline Data yang diuji & Mean & $\mathrm{t}$ & $p$ \\
\hline Pengetahuan & .267 & -6863 & 0.76 \\
Kemampuan & .253 & -4.596 & 0,46 \\
OHIS & .096 & .343 & 0.73
\end{tabular}

Tabel 9. Menunjukkan tidak terdapat perbedaan pengetahuan, kemampuan dan status kebersihan gigi dan mulut sebelum dan sesudah bimbingan menyikat gigi antara kelompok perlakuan dengan kelompok kontrol terlihat dari $p$ value $>0,05$.

Berdasarkan tabel 2 dan tabel 3, diketahui bahwa responden penelitian dengan jenis kelamin laki-laki berjumlah 36 orang $(60 \%)$ dan perempuan 24 orang (40\%), sedangkan responden berusia 8-9 tahun sebanyak 28 orang $(47,7 \%)$ dan usia $10-16$ sebanyak 32 orang $(53,3 \%)$. Hasil bimbingan menyikat gigi yang dilakukan selama 1 minggu di SLB Wiyata Dharma 4 Godean Sleman pada kelompok perlakuan yang menggunakan leaflet dan kelompok kontrol terhadap pengetahuan, sikap dan status kebersihan gigi dan mulut responden menunjukkan peningkatan.

a. Pengetahuan menyikat gigi anak tunagrahita sebelum dan sesudah penyuluhan.

Berdasarkan hasil penelitian diketahui pengetahuan menyikat gigi anak tunagrahita sebelum dilakukan penyuluhan menyikat gigi yang paling banyak adalah dengan kriteria sedang (43\%) tetapi setelah penyuluhan menyikat gigi dengan tambahan media leaflet pengetahuan menyikat gigi anak tunagrahita kriteria baik yang semula $20 \%$ meningkat menjadi $47 \%$. Peningkatan pengetahuan sebelum 
dan sesudah perlakuan terdapat perbedaan yang signifikan $(\mathrm{p}=0.00)$. Menurut peneliti, hal ini karena anak tunagrahita sebelumnya sudah memiliki pengetahuan awal mengenai menyikat gigi kemudian ditambah atau dilakukan pengulangan kembali terhadap pengetahuan sebelumnya membuat terjadinya peningkatan pengetahuan responden terhadap materi yang disampaikan. Pengetahuan seseorang dipengaruhi seberapa banyak informasi yang diperolehnya baik langsung maupuan tidak langsung, sehingga semakin banyak seseorang menerima informasi semakin baik pengetahuannya.

Hasil penelitian menunjukkan media berperan membantu meningkatkan hasil pembelajaran, peningkatan pengetahuan responden dalam penelitian ini kemungkinan diperkuat dengan penggunaan media lefleat saat penyuluhan yang dapat dibaca secara berulang oleh responden untuk memperkuat pemahamannya terhadap materi yang disampaikan. Metode penyuluhan dengan menggunakan media lefleat lebih dapat meningkatkan pengetahuan karena metode ini melibatkan seseorang dalam mempelajari sesuatu dengan baik apabila dia menggunakan lebih dari satu indera yaitu mendengar dan melihat, sesuai dengan asumsi bahwa semakin banyak indera yang digunakan, semakin banyak dan jelas pula pengetahuan dan pengertian Notoatmodjo (2003).

Hasil penelitian sejalan dengan penelitian Azizah, S., 2018 tentang pengaruh penyuluhan dan pelatihan melalui media leaflet terhadap pengetahuan kader PHBS di Kecamatan Rotolindo Kabupaten Tojo Una-una dimana diperoleh hasil penelitian terdapat pengaruh yang signifikan penyuluhan dengan pelatihan melalui media leaflet terhadap peningkatan pengetahuan kader PHBS. Hasil penelitian lain tentang penggunaan media leaflet dan video bahaya merokok pada remaja diketahui adanya perbedaan pengetahuan mahasiswa FKM UNISKA MAB antara sebelum dan sesudah diberi pendidikan kesehatan melalui leaflet, menurut peneliti hal ini karena laeflet membantu mengarahkan indera mahasiswa pada suatu objek sehingga memudahkan pemahaman (Kasman, dkk.2017)

Penyuluhan dengan leaflet yang memiliki kelebihan yakni pesan dapat dipelajar sesuai kebutuhan, minat dan kecepatan penerima pesan serta dapat dipelajari kapan saja dan bisa dibawa kemana saja. Agar telihat menarik biasanya didesain secara cermat dilengkapi ilustrasi dengan menggunakan bahasa yang sederhana, singkat dan mudah dipahami, media ini cocok untuk anak tunagrahita yang membutuhkan waktu lebih panjang dalam memerima pesan sehingga pesan harus disampaikan secara berulang-ulang. Fleksibilitas mental yang kurang pada anak tunagrahita mengakibatkan kesulitan dalam pengorganisasian materi yang dipelajari, sukar bagi anak tunagrahita menangkap pesan yang komplek (Sutjihati, 2007).

b. Kemampuan tehnik menyikat gigi anak tunagrahita sebelum dan sesudah bimbingan tehnik menyikat gigi.

Hasil penelitian terhadap kemampuan menyikat gigi anak tunagrahita menunjukkan ada perubahan signifikan sebelum dan sesudah perlakuan dengan angka $\mathrm{p}<0.05$ sedang pengaruh bimbingan menyikat gigi terhadap kemampuan menyikat gigi anak tunagrahita juga menunjukkan pengaruh yang signifikan ( $\mathrm{p}$ value $=0.00$ ). Peningkatan kemampuan baik yang semula hanya $27 \%$ meningkat menjadi $43 \%$ pada kelompok perlakuan, namun baik kelompok kontrol maupun kelompok perlakuan kriteria kemampuan terbanyak hanya pada kriteria sedang. 
Hal ini kemungkinan dipengaruhi karena sejak kecil manusia sudah belajar menyikat gigi untuk membersihkan gigi dan mungkin telah terbiasa tetap menggunakan teknik yang sama sampai usia dewasa, ini menyebabkan kesulitan dalam mengadopsi kemampuan yang baru saja diperoleh untuk diterapkan dalam kehudupan sehari-hari. Banyak diantara kita yang menggunakan teknik yang salah dalam menyikat gigi, sehingga banyak komentar tentang rajin menyikat gigi setiap hari, dua kali sehari pagi setelah sarapan dan malam sebelum tidur tetapi masih banyak masalah tentang kesehatan gigi dan mulut (Ramadhan, 2010).

Perilaku menggosok gigi pada anak harus dilakuakn dalam kehidupan seharihari tanpa ada paksaan. Kemampuan menggososk gigi secara baik dan benar merupakan faktor penting untuk perawatan kesehatan gigi dan mulut. Keberhasilan dalam menggosok gigi juga dipengaruhi oleh faktor penggunaan alat, frekuensi, waktu dan tehnik menggosok gigi yang tepat (Howink, 1994). Perubahan peningkatan kriteria baik kemampuan anak tunagrahita menurut peneliti adalah karena paparan media leaflet yang digunakan saat penyuluhan dan bimbingan tehnik menyikat gigi. Meningkatnya kemampuan anak tunagrahita terjadi karena ketertarikan anak tunagrahita pada media leaflet karena menyajikan materi dengan penggunaan gambar, warna-warna yang menarik serta bahasa yang mudah dipahami oleh anak tunagrahita. Pemilihan media leaflet sebagai media pembelajaran sangat tepat apabila digunakan untuk membangkitkan motivasi sehingga meningkatnkan hasil belajar siswa. Ketepatan memilih media yang digunakan dalam proses pembelajaran akan sangat berpengaruh terhadap tercapainya tujuan pendidikan dan pembelajaran (Bahri, 2013).

Perbedaan peningkatan perubahan pengetahuan dan kemampuan yang mencapai kriteria baik pada penelitian ini kemungkinan juga karena disebabkan perbedaan perlakuan antara kelompok perlakuan dan kelompok kontrol, dimana kelompok perlakuan pada saat bimbingan tehnik menyikat gigi disertai media laeflet yang berisi gambar-gambar cara menyikat gigi dengan warna yang menarik, sedangkan kelompok kontrol hanya berupa instruksi tindakan sehingga anak tunagrahita harus membayangkan terlebih dahulu instruksi yang disampaikan. Hasil penelitian sejalan dengan penelitian Cynthia, dkk., (2019), terbukti adanya peningkatan lebih tinggi pada pengetahuan dan sikap ibu terhadap tumbuh kembang balita dengan menggunakan metode penyuluhan dengan media leaflet dan dibandingkan dengan metode penyuluhan tanpa media leaflet. Penelitian yang dilakukan Lidya, 2018 menyimpulkan terdapat peningkatan sikap yang lebih tinggi sebelum dan sesudah penyuluhan dengan media leaflet dibandingkan tanpa media laflet.

Pendidikan kesehatan hakekaktnya merupakan suatu kegiatan atau usaha menyampaikan pesan kesehatan kepada masyarakat, kelompok maupun individu agar memperoleh pengetahuan yang lebih baik, dimana pengetahuan tersebut diharapkan berpengaruh kepada perubahan kemampuan dan perilaku sasaran. Faktor yang mempengaruhi suatu proses pendidikan disamping faktor masukannya sendiri juga dipengaruhi oleh faktor metode, materi, petugas dan juga alat bantu atau media yang digunakan untuk menyampaikan pesan (Notoatmodjo, 2010).

c. Kebersihan gigi dan mulut anak tunagrahita sebelum dan sesudah melakukan bimbingan tehnik menyikat gigi.

Hasil penelitian terhadap status kebersihan gigi dan mulut dalam penelitian ini menunjukkan perubahan yang signifikan antara sebelum dan sesudah perlakuan,

E-ISSN: 2657-0300 Lembaga Penelitian dan Penerbitan Hasil Penelitian Ensiklopedia $\quad 69$

P-ISSN: 2657-0319 
jika hasil pemeriksaan yang dilakukan sebelum penelitian diperoleh hasil anak tunagrahita yang memiliki kebersihan pada kriteria baik sebanyak 23\% maka diakhir penlitian anak tuna grahita dengan kriteri baik mecapai 50\%. Kebersihan gigi dan mulut untuk kriteria baik pada kelompok kontrol juga mengalami peningkatan namun tidak sebesar perubahan pada kelompok perlakuan, yakni dari 23\% berubah menjadi $37 \%$. Peningkatan status kebersihan gigi dan mulut kriteria baik kelompok perlakuan dan kelompok kontrol menurut peneliti terjadi dikarenakan responden telah dilatih dan telah terbiasa menerapkan teknik menyikat gigi yang telah diajarkan, meskipun ada beberapa responden yang belum terbiasa sehingga masih terdapat responden yang tidak dapat sempurna membersihkan sisa makanan yang tertinggal. Dalam melatih menyikat gigi yang belum terbiasa dilakukan, seseorang akan kesulitan melatih menyikat gigi yang diajarkan, tetapi seseorang yang serius dan sungguh-sungguh dalam melatih teknik menyikat gigi yang diajarkan maka sasaran akan bisa dan mahir sehingga akan mampu membersihkan gigi dan mulut dan terhindar dari penyakit gigi dan mulut (Subroto, 2010).

Hasil penelitian ini sejalan dengan hasil penelitian sebelumnya yang dilakukan pada 160 anak sekolah di Manado yang menunjukkan bahwa anak yang memiliki pengetahuan yang baik memiliki 2.2 kali untuk memiliki status kebersihan gigi dan mulut yang baik pula. Pentingnya peranan pengetahuan tentang kesehatan gigi dan mulut dalam membentuk perilaku dan sikap anak dalam menjaga kebersihan gigi dan mulut (Herijulianti, dkk,2002).

\section{Penutup}

Terdapat peningkatan pengetahuan, kemampuan dan status kebersihan gigi dan mulut anak tunagrahita sebelum dan sesudah perlakuan dengan $\mathrm{p}$ value $=0.00$ dan adanya pengaruh yang signifikan bimbingan menyikat gigi terhadap status kebersihan gigi dan mulut anak tunagrahita dengan $\mathrm{p}$ value $=0.00$.

\section{Ucapan Terima Kasih}

Ucapan terima Kasih kepada: Bapak Direktur dan Ketua Jurusan Keperawatan Gigi Poltekkes Yogyakarta, selaku penyandang dana dalam penelitian. Kepala sekolah, guru dan anak tunagrahita di SLB Wiyata Dharma IV Godean, serta semua pihak yang membantu selama penelitian berlangsung.

\section{Daftar Pustaka}

Azizah,S., Firdaus, Z., Kunoli, 2018, Pengaruh Penyuluhan dan Pelatihan Melaui Media Laeflet terhadap Pengetahuan Kader PHBS di Kecamatan Rotolindo Kabupaten Tojo Una-una, Jurnal Kesehatan Masyarakat, Vol. 8, No.2, hal. 159-164.

Cynthya, A.R., Dea, A.A., Hari, P. J., 2019, Perbandingan Penggunaan Metode Penyuluhan dengan dan tanpa Leaflet terhadap Pengetahuan dan Sikap Ibu tentang Tumbuh Kembnag Balita, Jurnal Kedokteran Gigi Dipenogoro, Vol. 8 No.1, h. 99-120,

Herijulianti, E., Indriani, T. S., Artini, S., 2002, Pendidikan Kesehatan Gigi, Jakarta, Buku Kedokteran, EGC 
Kasman, Noorhidayah, Kasuma Bakti Persada, Studi Eksperimen Penggunaan Media Leaflet dan Video Bahaya Merokok pada Remaja, Jurnal Publikasi Kesehatan Masyarakat Indonesia, Vol. 4, No. 2, h. 57-60.

Kementrian Kesehatan RI, 2018, Riset Kesehatan Dasar 2018 (Riskesdas 2018), Jakarta: Kemenkes RI.

Lossu F.M., Damajanty H.C.P., Vony N.S.W., 2015, Hubungan Pengetahuan Kesehatan Gigi dan Mulut dengan Indeks Gingiva Siswa SD Katolik 03 Frater Don Bosco Manado, Jurnal e-Gigi (eG), Vol. 03, No. 02, h. 27-33.

Motto, 2107, Gambaran Kebersihan Gigi dan Mulut pada Siswa Berkebutuhan Khusus di SLB YPAC Manado, Jurnal e-Gigi (e-G). Manado: Fakulatas Kedoktran Universitas Sam Ratulangi. Vol.5: 106-111.

Notoatmodjo, S. 2003 Perilaku Kesehatan, Jakarta: Rineka Cipta

Wati, G,M., 2012, Outbound Management Training untuk Meningkatkan Kemampuan Penyesuaian Diri Anak Tunagrahita: Educational Psychology Journal, Vol.1: 68-74.

Soebroto, I., 2009, Apa yang tidak dikatakan dokter tentang kesehatan gigi anda.Yogyakarta: Bookmarks

Tulangow,G., J., 2015, Gambaran Status Karies pada Anak Berkebutuhan Khusus di SLB YPAC Manado; Jurnal E-Gigi, Vol.3 No. 2; 610-615. 